\title{
Understanding Rural Parents' Behavioral Intention to Allow Their Children to Use Mobile Learning
}

\author{
David Mutambara and Anass Bayaga ${ }^{(\bowtie)}$ \\ University of Zululand, KwaDlangezwa, Empangeni, South Africa \\ vadmutambara@gmail.com, bayagaa@unizulu.ac.za
}

\begin{abstract}
Faced with many challenges resulting in learners' poor performance at the matriculation level, emphasis on Science, Technology, Engineering and Mathematics (STEM) education is in its infancy in South African's high schools. However, studies have shown that mobile learning (m-learning) can be used to mitigate the challenges of STEM education. Despite, the benefits of mobile learning to rural STEM learners, its full potential has not been realized because the adoption of m-learning depends on users' acceptance. Prior studies focused on teachers' and learners' acceptance of mobile learning. However, little is known about parents' acceptance of m-learning, especially in rural areas. This study explores the acceptance of m-learning by parents of rural high school STEM learners. The study proposes the parents' acceptance of m-learning model, which extends the technology acceptance model by introducing perceived social influence and perceived resources. Stratified random sampling was used to select 200 parents in the survey. Partial least squares structural equation modeling (PSL-SEM) was used to analyze data from 129 valid questionnaires. The proposed model explained $41 \%$ of the variance in parents' acceptance of mobile learning. Attitude towards the use was found to be the best predictor and the only factor that have a direct effect on behavioral intention to use mobile learning. However, all other factors have an indirect influence on behavioral intention. The findings revealed that for mobile learning to be successfully implemented in rural areas, resources need to be provided.
\end{abstract}

Keywords: Technology acceptance model $\cdot$ Perceived social influence $\cdot$ Perceived resources $\cdot$ STEM $\cdot$ Perceived usefulness $\cdot$ Perceived ease of use

\section{Introduction}

The integration of Science, Technology, Engineering and Mathematics (STEM) education is a growing area in both developed and developing countries [1]. Despite, STEM's fast growth, there is a lack of a universally accepted definition of STEM education [2]. In the study [3], STEM education was defined as “...fostering sustained engagement with the STEM disciplines where students can become competent contributors and critical participants in a range of STEM-related activities." What can be drawn from this definition is that STEM education aims at shifting teaching practices from teacher-centered into learner-centered and problem-based learning. 
As STEM education is in its infancy in South African's high schools, it is faced with many challenges resulting in learners' poor performance at the matriculation level $[4,8]$, especially in rural areas. Makgato [6] attributed this poor performance in STEM-related subjects in rural areas to lack of learning materials, science laboratory and equipment to promote effective teaching and learning. Lack of parental involvement in their children's education also contributes to learners' poor performance in STEM-related subjects [5]. All the challenges that rural high school STEM learners face lead to demotivation when learning STEM-related subjects [4]. Based on these studies [4, 5], one can conclude that there is no effective STEM teaching and learning in rural high schools.

Studies have shown that m-learning can be used to mitigate the challenges of STEM education [7-9]. M-learning enables the use of visualized science experiments. This can positively influence learners' knowledge of science, which can enable them to give complete descriptions of scientific concepts [9]. Furthermore, m-learning makes studying materials available to learners anytime anywhere [7]. One can conclude that even though there are challenges in rural high schools, learners can still benefit from mlearning as they have access to learning materials and to visualize experiments using their mobile devices [7, 9]. According to Kong [8], m-learning improves parents' involvement in their children's learning, which in turn improves learners' motivation and performance in STEM-related subjects.

However, despite the positive effects m-learning can bring to rural STEM learners and the ubiquity of mobile devices, its adoption into the classroom is far below the expected rate [10]. Davis [11] stated that the successful adoption of any information system contingent on the user's acceptance. As a consequence of Davis' [11] assessment, it could be argued that successful implementation of m-learning in high schools of developing countries requires investigation of all stakeholders' attitudes. A plethora of studies has been conducted to identify factors that affect the acceptance of mobile learning [12-15]. However, a key issue is whether academics have adopted an adequately broad approach when investigating the attitudes of the main players in a high school instructional setting [16]. Most of these m-learning acceptance studies have concentrated on teachers [14, 17] and learners [13, 17]. Little is known about the parents' attitude towards m-learning, especially in rural areas of developing countries. Teacher and learner preferences aside, parents have the last decision on whether to use m-learning. Parents' roles in m-learning include; financial support, encouragement, purchasing of the mobile device and data, monitoring that the devices are used in a meaningful way that enhances learning [8]. In spite of parents playing an important role in the adoption of m-learning, their attitude towards mobile learning has not been given the attention it deserves [19]. Ford [18] stressed the need to carry out studies on the acceptance of m-learning in the South African context and not to blindly follow examples in developed countries. On the basis of the argument thus far, the current research sought to examine the perceptions of parents of rural high school STEM learners towards m-learning.

Identifying and understanding these factors is important for the successful implementation of m-learning. Hence, this study used the technology acceptance model (TAM) to investigate the factors that predict rural high school STEM learners' parents' attitudes towards m-learning. Specifically, the study seeks to answers the following research questions: 
RQ 1: What is the effect of parents' perceived usefulness, perceived ease of use, attitude towards the use, perceived resources and perceived social influence on their behavioral intention to use m-learning?

RQ2: What is the relative importance of each of these factors in explaining parents' behavioral intention to use m-learning?

The findings of this study may provide more insight on m-learning acceptance in developing counties, and help policymakers and all other stakeholders in education on how to successfully implement m-learning in rural areas.

\section{Literature Review and Model Development}

\subsection{Literature Review}

Traditionally, the integration of m-learning has considered the home environment as the basis for extending formal learning beyond the wall of the classroom [16]. However, there is a big difference between what teachers hoped for and what mobile devices are actually being used for at home. At home mobile devices are mostly used for communication and playing games [39]. The most effective way of integrating mlearning into schools is through involving parents [8]. Parents' beliefs about m-learning influence their children's use [19]. Studies have shown that parents have contradictory attitudes towards the integration of m-learning in children's education [16, 19, 39]. In a study carried out by Genc [39] on the perception of parents towards mobile learning, the results show that about $46.88 \%$ of parents were having negative perceptions, while $26.88 \%$ were neutral while $26.56 \%$ were having positive perceptions towards mobile learning. Genc's [39] results were congruent to Bourgonjon et al's [16] findings, who stated that some parents expressed negative perception towards the use of mobile digital games-based learning. In both studies [16, 39], parents who had positive perceptions towards the integrating technology cited the usefulness of it in their children's education. However, parents were concerned about the health and social issues associated with overexposure to technology [16]. A plethora of studies has shown that parents' PEOU has a positive effect on their ATT and PU [10, 16, 17, 19, 29, 39]. However, there is some inconsistency when it comes to the relationship between parents' PEOU and their BI to allow their children to use m-learning. Studies [10] and [16] found that PEOU does not necessarily have a direct effect on BI. On the contrary, Alshmrany et al. [17] reported that PEOU has a positive direct effect on BI. Tsuei [19] studied the effect of parents' PSI on their PU and PEOU. The results showed that parent-teacher communication positively influenced both PU and PEOU. However, the communication between children and their parents only influenced parents' PU but not PEOU [19]. These results show that social influence plays an important role in parents' acceptance of information and communication technology (ICT) learning. Tsuei [19] highlighted the need to build partnerships between schools and parents for the successful integration of ICT learning. 


\subsection{Technology Acceptance Model (TAM) Variables}

TAM and the Unified Technology of Acceptance and Use Theory (UTAUT) are the commonly used models to study factors that affect the acceptance of m-learning. In this study, TAM was selected because it is considered to be robust and it is mostly used model for the study of the adoption of technology in educational contexts [23, 24].

TAM expounded upon the ideas of the Theory of Reasoned Action [20]. Perceived usefulness and perceived ease of use are the two pillars of TAM. These two pillars predict users' attitudes toward the use, which, in turn, affect behavioral intention to use an information system [11]. Venkatesh [21] suggested that more variables that are context-related can be added to TAM to improve its explanatory power of the acceptance of the technology in question as further explained [13].

\section{Behavioral Intention to use (BI)}

BI was defined by Fang [25] as," ... the cognitive representation of a person's readiness to perform a given behavior", and it is considered to be the best antecedent of behavior." Thus, TAM assumes that parents' adoption is determined by their BI to use m-learning [16].

\section{Attitude Towards the Use (ATT)}

Attitude toward a behavior is defined as, “... the degree to which a person has a favorable or unfavorable evaluation or appraisal of the behavior studied" [26]. That is beliefs and attitudes play an important role in rejecting or accepting m-learning [28]. Parents' attitudes towards m-learning positively affect their behavioral intention to use [19]. This finding is congruent to the finding of Davis [11] and Dutota et al. [26]. Therefore, the hypothesis:

H1: Attitude toward use has a positive effect on behavioral intention.

\section{Perceive Usefulness (PU)}

In the m-learning context, PU is explained as a person's perception that using mlearning will improve his or her teaching and learning [27]. One of the main factors behind parents' adoption of m-learning is the perception that m-learning is going to improve the performance of their children [16, 19]. Bourgonjon [16] studied the factors that make parents accept digital game-based learning and found that learning opportunities were the single best predictor of parents' preference for video games. If parents perceive advantages in using m-learning, their attitude towards the use of these technologies will be more positive. Therefore, the hypotheses:

H2: Perceived Usefulness has a positive effect on perceived attitude towards the use.

H3: Perceived Usefulness has a positive effect on behavioral intention to use.

\section{Perceived Ease of Use (PEOU)}

In the m-learning context, PEOU can be defined as the extent to which users believe that adopting m-learning would be free from effort. When parents perceive that their children can use m-learning for learning STEM-related subject with minimum effort, they will have a positive attitude towards it, will realize its utility and adopt it. Thus, the hypotheses:

H4: Perceived ease of use has a positive effect on perceived usefulness.

H5: Perceived ease of use has a positive effect on behavioral intention to use.

H6: Perceived ease of use has a positive effect on attitude towards the use. 


\section{Perceived Resources (PR)}

PR is defined as "... the extent to which an individual believes that he or she has the personal and organizational resources needed to use an information system" [30]. Perceived resources was found to have a positive effect on PU, PEOU and ATT [3133]. In the studies [31-33], researchers investigated the effects of the availability of resources on teachers' acceptance of ICT into the classroom. They found that lack of laptops, computer technical support from peers negatively affected the integration of ICT into the classroom. Mboweni [34] found that most of the rural parents rely on social grants and have financial problems. M-learning requires money for purchasing of devices and data. Basing on the results of Lim [31] and Mboweni [34], one can learn that rural parents' perceived resources will affect their PU and PEOU towards the use of m-learning. Therefore, the hypotheses:

H7: Perceived resources has a positive effect on perceived usefulness

H8: Perceived resources has a positive effect on perceived ease of use.

\section{Perceived Social Influence (PSI)}

PSI is similar to the theory of reasoned action's subjective norm [20], which was defined as “... a person's perception that most people who are important to him think he should or should not perform the behavior in question". In this study, PSI is when parents of high school STEM learners consider the view of those who are important to them whether they should or should not allow their child to use m-learning. Parents of STEM learners in rural areas are influenced by messages about m-learning. This was suggested by Venkatesh et al. [21] who stated that people internalize the beliefs of other people and make them part of their own belief system. If parents think that their community, children, and teachers are expecting them to accept the use of m-learning, they would have a positive attitude towards m-learning. Therefore, the hypothesis:

H9: Perceived social influence has a positive effect on perceived usefulness

H10: Perceived social influence has a positive effect on attitude towards the use.

On the basis of the theoretical underpinning, a hypothetical model is in Fig. 1.

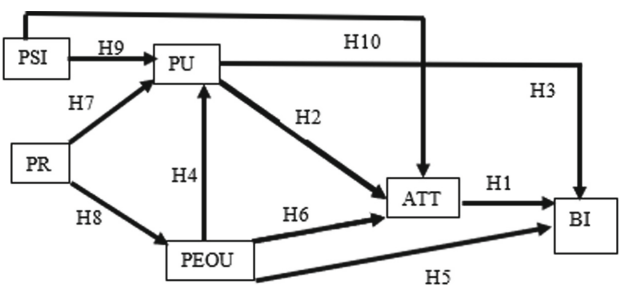

Fig. 1. The parents' acceptance of mobile learning model

\section{Methods}

\subsection{Research Design}

The research followed a quantitative approach, where survey demographic and opinion-related data were collected from parents using a questionnaire. Firstly, the data from parents were explored using descriptive statistics. Secondly, the partial least squares structural equation model (PLS-SEM) was used to test the hypothesized model. 


\subsection{Participants}

The study adopted stratified sampling to collect data [35]. All high schools in rural areas in King Cetshwayo District were grouped using their quintiles. To ensure that homogenous elements form a stratum, schools in the same quintile were grouped. Three strata were formed. Simple random sampling was then used to select four schools in each stratum. Simple random sampling was also used to select 200 grade, 12 STEM learners, from the selected schools. The selected learners were given questionnaires to give to their parents and $129(65 \%)$ valid questionnaires were collected. Using Chin's [36] recommendation of 10 times larger than the number of items of the construct with most items, the sample size exceeds the recommended 50.

\subsection{Measures}

Firstly, the parents filled in questions about demographical information. Secondly, respondents answered the main part of the questionnaire, which comprised of scales measuring the constructs of the model. The questionnaire was adopted from previous studies $[19,33]$ and modified to suit the needs of the current study. The measurement instrument consists of six constructs making a total of 25 items. The questionnaire was developed and translated into IsiZulu and distributed both in English and IsiZulu. The respondents were asked to choose the language they are comfortable with. All items were measured on a 7-point Likert-type scale with 1 corresponding to "strongly disagree" and 7 to "strongly agree."

\subsection{Analysis Technique}

Partial Least Squares Structural Equation Modeling (PLS-SEM) was used to analyze data making use of the software SmartPLS 3. One of the functions of PLS-SEM is the prediction of the target variable [10] in this case rural parents whose children are pursuing STEM's behavioral intention to allow their children to use m-learning. PLSSEM was also used to assess the predictive power of antecedent variables. The study followed Chin's [36] two-stage approach of model analysis. First, the reliability and validity of different model variables were assessed to confirm the quality of the outer model. In the second step, the relationships within the structural model were assessed by testing the significance of the relationships, explained variance of the endogenous variables and predictive power of different variables [10].

\section{Data Analysis Results}

\subsection{Measurement Model Assessment}

The outer model describes the association between items and the latent variables. Convergent validity and discriminant validity of the outer model needs to be assessed $[37,38]$, in order to ascertain the goodness of fit of the out model. Convergent validity assesses the degree to which there is a high correlation between the latent variable which are theoretically identical, while discriminant validity assesses the degree to which a construct differs from other constructs $[37,38]$. 
The results (see Fig. 2) show that almost all reflective indicators have loadings higher than 0.7 [37] except ATT1 (0.692), PR4 (0.612) and PU4 (0.671). The items were returned due to the exploratory nature of the study and removing them did not result in an increase in the composite reliability [37]. The results confirm item reliability. The results (Appendix 4) also confirm convergent validity as well, with Cronbach's alpha $(\alpha)$ greater than 0.7 , composite reliability (CR) above 0.6 and average explained extracted (AVE) values greater than 0.5 [37].

\section{Discriminant Validity}

The heterotrait-monotrait ratio of correlations (HTMT) and the Fornell-Larcker criterion were used to assess discriminant validity [37]. Results (Appendix 1) show that all the root of AVE values were higher than inter-construct correlations and all the HTMT values were under 0.85 [37]. The results confirm discriminant validity. Overall, the indicator reliability, internal consistency reliability, convergent validity and discriminant validity tests conducted on the measurement model were satisfactory.

\subsection{Structural Model Assessment}

After ascertaining the suitability of the outer model, the inner model was examined, and the hypotheses were tested. Before assessing the inner model, the variance inflation factor (VIF) was used to assess collinearity issues. All the VIF values were less than 4 [39], indicating that there were no collinearity issues. Results in (Appendix 2) and Fig. 2 summarize the inner model and the hypotheses testing results. Figure 2 shows the $\mathrm{R}^{2}$ of the model. The model explains $24 \%$ of PU $19 \%$ of PEOU, $43 \%$ ATT and $41 \%$ of the variance of rural parents' BI for their children to use m-learning. The variance explained in rural parents' ATT and BI is considered moderate, while, variance explained in PU and PEOU is considered small [36]. The results of Fig. 2 also shows the standardized path coefficients. The results show that all model's antecedents predict rural parents' behavioral intention to allow their children to use mobile learning for learning STEM. Results (Appendix 1) show the results of the bootstrapping procedure. The results show that all the hypotheses were supported except H3 and H5. Additionally, the results in (Appendix 1) show the effect size of these relations. Two relations (ATT $->$ BI and PEOU $->$ ATT) have large effect size, PR $->$ PEOU has a

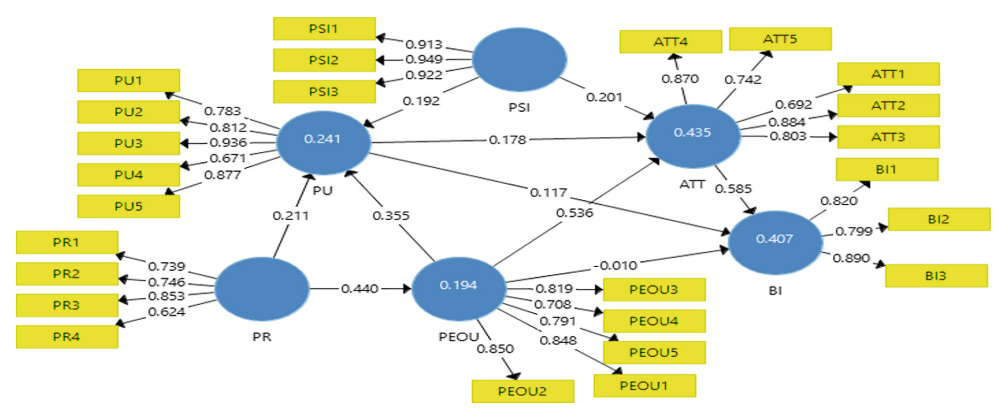

Fig. 2. Structural equation model analysis 
medium effect size while the last five (PEOU $\rightarrow$ PU, PR $->$ PU, PSI $->$ ATT, PSI $>$ PU and PU $->$ ATT) have small effect size. The $Q^{2}$ values range from 0.16 to 0.23 , indicating a medium predictive relevance [37].

To answer research question 2, the observation of total effects (Appendix 3) was used. The results show that the best predictors of parents' BI to allow their children to use mobile learning to STEM-related subjects are ATT, PEOU and PR.

\section{Discussions}

RQ1: This study sought to examine the effects of PU, PEOU, ATT, PSI and PR on the behavioral intention to allow children to use m-learning for rural parents. The results show that the model was appropriate for determining the rural parents' acceptance of m-learning as it explains $41 \%$ of the variance in BI. It was found that all the antecedents predict behavioral intention to use m-learning. However, only parents' ATT has a direct effect on BI. It would be reasonable to infer that when rural parents have positive feelings towards the use of m-learning, these positive feelings will reinforce their intention to allow their children to use m-learning to learn STEM-related subjects. Parents' ATT mediates the effect of their PU, PSI, PR and PEOU on their BI. The results show some notable differences from prior adoption studies $[10,11,13]$. In contrary to the previous finding, PU has an insignificant effect on rural parents' BI [13, 19]. The results show that rural high school STEM learners' parents are not acquainted with the usefulness of mobile devices in the classroom. However, the results also confirm the finding of [19], who found that PU indirectly influences users' BI by the mediation of ATT. This might mean that even though rural parents have limited knowledge about the benefits that m-learning bring into STEM learning, that little knowledge they possess positively affects their attitudes towards the use of m-learning for STEM learning.

In contrary to the findings of Davis [11], the current study found that PEOU predicts ATT, better than PU. This shows that rural parents consider the effort needed to learn to use m-learning more important when adopting it than its utility. The finding might be due to parents belonging to the "digital immigrants" generation which struggle to use mobile devices to carry out specific tasks. The results also show that parents are not indifferent to what other people (teachers, society and children) think about m-learning, as their ATT towards m-learning was influenced by their PSI better than their PU. These results are line with the findings of Tsuei [19], who found that teacher-parent and children-parents communication influenced parents' technology acceptance. PSI also positively affect PU and BI by the mediating of ATT. The results suggest that rural parents value what people important to them say about the use of $\mathrm{m}$ learning for STEM learning. Therefore, it is important for teachers and learners to provide rural parents with an awareness of the potential of m-learning for STEMrelated subjects.

Regarding PR, the results show that it positively affects both PU and PEOU. The results also show that PR has an indirect effect on BI through PEOU and ATT. This finding was not surprising due to the rural environment in which the study was carried. Most of the families in rural areas are living in poverty and depend on social grants as 
their source of income [34]. It is also interesting to note that PR has indirect effects on ATT and PU by the mediating effect of PEOU. The results suggest that for rural parents, the availability of resources affects the usefulness and ease of use, which in turn affects parents' attitudes towards m-learning. The conclusion that can be drawn from these results is that, for a successful implementation of m-learning for STEM learning in rural areas, resources need to be provided. Based on the current findings, the following suggestions can be made to mobile developers and instructional designers and the Department of Basic Education (DBE), in line with Li et al. [13] and Nikou et al. [14] who studied learners' and teachers' acceptance of m-learning. Mobile developers should make m-learning platforms user-friendly and contain as much learning material and assessments as possible. This is because rural parents, teachers and learners consider utility and ease of use to be important when adopting m-learning. The DBE should provide resources needed for mobile learning. The researchers suggest that the DBE should supply rural STEM learners with tablets. Furthermore, the DBE should use offline portals to support m-learning in rural areas, make some partnerships with cellular network service providers to allow some educational platforms and websites to be accessed freely, this will remove the burden of buying data from rural parents.

RQ2: The ordinal strength of the predictors of rural parents' BI to use mobile learning is as follows: ATT $(\beta=0.629, \mathrm{p}<0.01)$, PEOU $(\beta=0.374, \mathrm{p}<0.01)$, PR $(\beta=0.189, \mathrm{p}<0.01)$, PSI $(\beta=0.148, \mathrm{p}<0.01)$ and lastly PU $(\beta=0.113, \mathrm{p}<0.05)$.

One limitation in the current study is that it focuses on parents of STEM learners. Therefore, the generalization of the findings of this study to all high school and primary parents of rural areas should be done with caution. Future studies should study perceived resources by clearly differentiating the different resources needed to support mlearning. It would be interesting to study perceived social influence to clearly determine the actual group (teachers, children or society) that affect rural parents' attitudes towards m-learning.

\section{Conclusion}

Based on the results of this study, contrary to the findings of Davis [11], only parents' attitudes towards m-learning have a direct effect on rural parents' behavioral intention to allow their STEM learners to use m-learning. Additionally, the results support the suggestion by Venkatesh et al. [22], who proposed that more variables that are contextrelated can be added to TAM to study the acceptance of an information system. In this study perceived social influence and perceived resources were added to TAM. The results showed that perceived social influence and perceived resources had a positive indirect influence effect on their behavioral intention to use mobile learning. The results also show that all the variables in the model predict behavioral intention to use $\mathrm{m}$ learning. The predicting power of these variables is as follows: ATT, PEOU, PR, PSI and PU. The lessons that can be drawn from the study are that rural parents' attitudes towards m-learning and the perceived ease of use are the most important factors that they consider when accepting m-learning. This might mean that parents expect their children to be trained on how to use m-learning before its implementation. Furthermore, infrastructure, mobile devices and data need to be made available for mobile learning to be successfully adopted in rural areas. 


\section{Appendix}

Appendix 1. Discriminant validity analysis

\begin{tabular}{|c|c|c|c|c|c|c|c|c|c|c|c|c|}
\hline & \multicolumn{6}{|c|}{ Fornell-Larcker criterion } & \multicolumn{6}{|c|}{ HTMT } \\
\hline & ATT & BI & PEOU & PR & PSI & PU & ATT & $\mathrm{BI}$ & PEOU & PR & PSI & PU \\
\hline ATT & 0.802 & & & & & & & & & & & \\
\hline BI & 0.630 & 0.837 & & & & & 0.748 & & & & & \\
\hline PEOU & 0.600 & 0.392 & 0.805 & & & & 0.675 & 0.440 & & & & \\
\hline $\mathrm{PR}$ & 0.243 & 0.160 & 0.439 & 0.744 & & & 0.288 & 0.192 & 0.527 & & & \\
\hline PSI & 0.184 & 0.187 & 0.068 & 0.288 & 0.928 & & 0.204 & 0.208 & 0.084 & 0.365 & & \\
\hline PU & 0.433 & 0.366 & 0.435 & 0.316 & 0.106 & 0.821 & 0.480 & 0.401 & 0.476 & 0.367 & 0.118 & \\
\hline
\end{tabular}

Appendix 2. Path coefficient

\begin{tabular}{l|l|l|l|l|l|l|l}
\hline Hypothesis & Relation & Standard Beta & \multicolumn{2}{l|}{$\begin{array}{l}\text { Confidence } \\
\text { interval }\end{array}$} & $\mathrm{f}^{2}$ & P values & Result \\
\hline H1 & ATT -> BI & $0.585^{* *}$ & 0.406 & 0.710 & 0.349 & 0.000 & Supported \\
\hline H6 & PEOU -> ATT & $0.536^{* *}$ & 0.356 & 0.688 & 0.405 & 0.000 & Supported \\
\hline H5 & PEOU -> BI & 0,01 & $-0,171$ & 0.176 & 0.000 & 0.922 & Not Supported \\
\hline H4 & PEOU -> PU & $0.355^{* *}$ & 0.199 & 0.502 & 0.133 & 0.000 & Supported \\
\hline H8 & PR -> PEOU & $0.440^{* *}$ & 0.294 & 0.553 & 0.240 & 0.000 & Supported \\
\hline H7 & PR -> PU & $0.211^{*}$ & 0.055 & 0.371 & 0.043 & 0.033 & Supported \\
\hline H10 & PSI $->$ ATT & $0.201^{* *}$ & 0.073 & 0.314 & 0.070 & 0.006 & Supported \\
\hline H9 & PSI $->$ PU & $0.192^{* *}$ & 0.078 & 0.264 & 0.044 & 0.001 & Supported \\
\hline H2 & PU -> ATT & $0.178^{* *}$ & 0.037 & 0.313 & 0.045 & 0.034 & Supported \\
\hline H3 & PU -> BI & 0.117 & $-0,077$ & 0.265 & 0.018 & 0.269 & Not Supported \\
\hline
\end{tabular}

Appendix 3. Total effects

\begin{tabular}{l|l|l|l|l}
\hline Relation & Standard beta & Standard error & T-statistics & Confidence interval \\
\hline ATT $->$ BI & 0.629 & 0.054 & $11.610^{* *}$ & $0.523-0.705$ \\
\hline PEOU -> ATT & 0.595 & 0.094 & $6.315^{* *}$ & $0.431-0.728$ \\
\hline PEOU -> BI & 0.374 & 0.075 & $4.977 * *$ & $0.246-0.492$ \\
\hline PEOU -> PU & 0.355 & 0.097 & $3.649^{* *}$ & $0.196-0.508$ \\
\hline PR -> ATT & 0.301 & 0.059 & $5.097 * *$ & $0.190-0.384$ \\
\hline PR -> BI & 0.189 & 0.046 & $4.098^{* *}$ & $0.109-0.254$ \\
\hline PR -> PEOU & 0.440 & 0.086 & $5.126^{* *}$ & $0.274-0.556$ \\
\hline PR -> PU & 0.371 & 0.090 & $4.130^{* *}$ & $0.217-0.505$ \\
\hline PSI $->$ ATT & 0.235 & 0.069 & $3.401^{* *}$ & $0.132-0.354$ \\
\hline PSI $->$ BI & 0.148 & 0.046 & $3.204^{* *}$ & $0.079-0.226$ \\
\hline PSI -> PU & 0.192 & 0.059 & $3.275^{* *}$ & $0.086-0.279$ \\
\hline PU -> ATT & 0.180 & 0.087 & $2.081^{*}$ & $0.044-0.323$ \\
\hline PU -> BI & 0.113 & 0.058 & $1.966^{*}$ & $0.027-0.218$ \\
\hline
\end{tabular}

Significant at $\mathrm{p}^{* *}=<0.01, \mathrm{p}^{*}<0.05$; 
Appendix 4. Measurement model

\begin{tabular}{l|l|l|l|l|l|l}
\hline Construct & PR & PU & PEOU & PSI & ATT & BI \\
\hline Cronbach's alpha $(\alpha)$ & 0.737 & 0.877 & 0.865 & 0.920 & 0.858 & 0.790 \\
\hline CR & 0.831 & 0.911 & 0.902 & 0.949 & 0.899 & 0.875 \\
\hline AVE & 0.554 & 0.673 & 0.648 & 0.861 & 0.642 & 0.701 \\
\hline
\end{tabular}

\section{References}

1. El-Deghaidy, H., Mansour, N.: Science teachers' perceptions of STEM education: possibilities and challenges. Int. J. Learn. Teach. 1(1), 51-54 (2015)

2. English, L.D.: STEM: challenges and opportunities for mathematics education. In: Paper Presented at the Proceedings of the 39th Conference of the International Group for the Psychology of Mathematics Education, Hobart, Tasmania (2015)

3. Burke, L., Francis, K., Shanahan, M.: A horizon of possibilities: a definition of STEM education. Paper Presented at the STEM 2014 Conference, Vancouver (2014)

4. Chan, Y.L., Norlizah, C.H.: Students' motivation towards science learning and students' science achievement. Int. J. Acad. Res. Progressive Educ. Dev. 6(4), 174-189 (2017)

5. Modisaotsile, B.M.: The failing standard of basic education in South Africa AISA POLICY brief: Africa Institute of South Africa (2012)

6. Makgato, M.: Factors associated with poor performance of learners in mathematics and physical science in secondary schools in Soshanguve, South Africa. Africa Educ. Rev. 4(1), 89-103 (2007)

7. Criollo, C.S., Luján-Mora, S., Jaramillo-Alcázar, S.: Advantages and disadvantages of Mlearning in current education. Paper presented at the 2018 IEEE World Engineering Education Conference (EDUNINE) (2018)

8. Kong, S.C.: Parents' perceptions of e-learning in school education: implications for the partnership between schools and parents. Technol. Pedagogy Educ. 27(1), 15-31 (2018)

9. Pinker, S.: How the Mind Works. W. W. Nortan, New York (1997)

10. Sánchez-Prietoa, J.C., Hernández-Garcíab, Á., García-Peñalvoa, F.J., Chaparro-Peláezb, J., Olmos-Migueláñeza, S.: Break the walls! Second-order barriers and the acceptance of mLearning by first-year pre-service teachers. Comput. Hum. Behav. 95, 158-167 (2019)

11. Davis, F.D.: Perceived usefulness, perceived ease of use, and user acceptance of information technology. MIS Q. 13(3), 319-340 (1989)

12. Estrieganaa, R., Medina-Merodiob, J.-A., Barchino, R.: Student acceptance of virtual laboratory and practical work: an extension of the technology acceptance model. Comput. Educ. 135, 1-14 (2019)

13. Li, R., Meng, Z., Tian, M., Zhang, Z., Ni, C., Xiao, W.: Examining EFL learners' individual antecedents on the adoption of automated writing evaluation in China. Comput. Assist. Lang. Learn. 32(7), 784-804 (2019)

14. Nikou, S.A., Economides, A.A.: Factors that influence behavioral intention to use mobilebased assessment: a STEM teachers' perspective. Br. J. Educ. Technol. 50(2), 587-600 (2019)

15. Saroia, A.I., Gao, S.: Investigating university students' intention to use mobile learning management system. Innovations Educ. Teach. Int. 56(5), 569-580 (2018)

16. Bourgonjon, J., Valcke, M., Soetaert, R., Wever, Bd, Schellens, T.: Parental acceptance of digital game-based learning. Comput. Educ. 57, 1434-1444 (2011)

17. Alshmrany, S., Wilkinson, B.: Factors influencing the adoption of ICT by teachers in primary schools in Saudi Arabia: teachers' perspectives of the integration of ICT in primary education. IJACSA 8(12), 143-156 (2017) 
18. Ford, M., Botha, A.: A pragmatic framework for integrating ICT into education in South Africa. Paper Presented at the IST-Africa 2010 Conference Proceedings (2010)

19. Tsuei, M., Hsu, Y.Y.: Parents' acceptance of participation in the integration of technology into children's instruction. Asia Pacific Edu. Res. 28, 457-467 (2019)

20. Fishbein, M., Ajzen, J.: Beliefs, Attitudes, Intention, and Behavior: An Introduction of Theory and Research Reading. Addison Wesley Publishing, Reading (1975)

21. Venkatesh, V., Davis, F.D.: A theoretical extension of the technology acceptance model: four longitudinal field studies. Manage. Sci. 46(2), 186-204 (2000)

22. Venkatesh, V., Morris, M.G., Davis, G.B., Davis, F.D.: User acceptance of information technology: towards a unified view. MIS Q. 27(3), 425-478 (2003)

23. Park, S.Y.: An analysis of the technology acceptance model in understanding university students' behavioral intention to use e-learning. Educ. Technol. Soc. 12(3), 150-162 (2009)

24. Teo, T.: Modelling technology acceptance in education: a study of pre-service teachers. Comput. Educ. 52(5), 302-312 (2009)

25. Fang, C.S.O.Y., Kayad, F., Misieng, J.: Malaysian undergraduates' behavioural intention to use LMS for online English learning: an extended self-directed learning technology acceptance model. J. ELT Res. 4(1), 8 (2019)

26. Dutota, V., Bhatiasevib, V., Bellallahom, N.: Applying the technology acceptance model in a three-countries study of smartwatch adoption. J. High Technol. Manage. Res. 30, 1-14 (2019)

27. Cheng, E.W.L.: Choosing between the theory of planned behavior (TPB) and the technology acceptance model (TAM). Education Tech. Research Dev. 67(1), 21-37 (2019)

28. Venkatesh, V., Bala, H.: Technology acceptance model 3 and a research agenda on interventions. Decis. Sci. 39(2), 273-315 (2008)

29. Yorganci, S.: Investigating students' self-efficacy and attitudes towards the use of mobile learning. J. Educ. Pract. 8(6), 181-185 (2017)

30. Mathieson, K., Peacock, E., Chin, W.W.: Extending the technology acceptance model: the influence of perceived user resources. ACM SIGMIS Database 32(3), 86-112 (2001)

31. Lim, C.P., Khine, M.S.: Managing teachers' barriers to ICT integration in Singapore schools. J. Technol. Teacher Educ. 14, 97-125 (2006)

32. Teo, T., Lee, C., Chai, C.S.: Understanding pre-service teachers' computer attitudes: applying and extending the technology acceptance model. J. Comput. Assist. Learn. 24(2), 126-143 (2007)

33. Sivo, S.A., Ku, C.-H., Acharya, P.: Understanding how university student perceptions of resources affect technology acceptance in online learning courses. Australas. J. Educ. Technol. 34(4), 72-91 (2018)

34. Mboweni, L.: Challenges and factors contributing to learner absenteeism in selected primary schools in Acornhoek. Master of Education, Unisa (2014)

35. Creswell, J.W.: Research Design: Qualitative, Quantitative, and Mixed Methods Approaches, 4th edn. SAGE Publications Inc., Thousand Oaks (2014)

36. Chin, W.W. (ed.): The Partial Least Squares Approach for Structural Equation Modelling. Lawrence Erlbaum Associates, Hillsdale (1998)

37. Hair, J.F., Hult, G.T.M., Ringle, C.M., Sarstedt, M.: A Primer on Partial Least Squares Structural Equation Modeling (PLS-SEM). SAGE Publications, Thousand Oaks (2016)

38. Salloum, S.A., Al-Emran, M., Shaalan, K., Tarhini, A.: Factors affecting the E-learning acceptance: a case study from UAE. Educ. Inf. Technol. 24, 509-530 (2019). https://doi.org/ 10.1007/s10639-018-9786-3

39. Genc, Z.: Parents' perceptions about the mobile technology use of preschool aged children. Procedia Soc. Behav. Sci. 146, 55-60 (2014) 